\title{
PREDICTING WORK-FAMILY AND FAMILY- WORK CONFLICT FROM WORK AND FAMILY DOMAIN: A LONGITUDINAL STUDY
}

\author{
ZAITON HASSAN \\ HANA HAMIDI \\ Faculty of Cognitive Sciences and Human Development \\ Universiti Malaysia Sarawak
}

\begin{abstract}
Although work-family conflict studies are available in Malaysia, most rely on cross-sectional design and focus on women. This study uses the longitudinal design on a heterogeneous sample which is aimed to enhance the understanding of the antecedents of work-family conflict (WFC) and familywork conflict (FWC) from work and family demands and resources. The respondents were 296 employees in diverse industries from six public and private organizations in Kuching, Sarawak. Two surveys were conducted over a three-month interval. Structural Equation Modeling via AMOS 7.0 was used to analyse the data. The study found that the respondents reported higher WFC than FWC. Demands from work predicted WFC positively while resources from work predicted WFC negatively. None of the demands and resources from work and family predicted FWC. The findings implied the importance of organizations in influencing the work-family balance of the employees.
\end{abstract}

Keywords: Work-family conflict (WFC), family-work conflict (FWC), demands, resources.

\section{Introduction}

The capacity to balance work and family is recognized as one of the primary social challenges in this era Halpern (2005) in Grzywacz and Carlson (2007). For instance, a recent report in the United States indicated that more than 90 per cent of American mothers and 95 per cent of American fathers report experiencing work-family conflict, with the majority of them in the middle class (Anonymous, 2010). Lack of balance, indicated by high work-family and family-work conflicts are related to negative consequences to individuals' employees and organisations. 
Greenhaus and Beutell (1985) defined work-family conflict (WFC) as 'a form of inter- role conflict, in which the demands of work and family roles are incompatible in some respect, so that participation in one role is more difficult because of participation in the other role'(p. 77). Scholars divided WFC into two directions; i.e. work can interfere with family responsibilities (work-to-family conflict - WFC) and family can interfere with work responsibilities family-to-work conflict - (FWC) (e.g.; Carslon, 2000; Frone, Russell \& Cooper, 1992)

Previous researches have shown that WFC were related to greater turnover intentions, greater sickness absences (Hacker \& Doolen, 2003), less job, family, community and life satisfaction (Hassan, Dollard \& Winefield, 2010). In addition, employers' policies and practices in managing work and non-work issues have an influence on society including children, community, individuals and personal and spiritual development (Friedman \& Greenhaus, 2000).

Since the research on work-family interface started in the Western countries, the literature is dominated with Western perspectives. However, culturally, individualist (mostly Western countries) and collectivist (mostly Eastern countries) view work and family differently. While work is separated from private life in individualist society, work and life are integrated in collectivist society (Hofstede, 1984). To illustrate, life satisfaction of Hong Kong employees is influenced primarily by WFC, while that of American employees is influenced primarily by FWC (Aryee, Fields \& Luck, 1999). Yang, Chen, Choi \& Zou (2000) research in the United States and China found that family demands had stronger effects on WFC for American employees while work demand had stronger effects on Chinese employees.

Most work-family studies relied on cross-sectional design which subject to common method variances and bias (Jansen, Kant, Kristensen \& Nijhuis, 2003). Furthermore, by using this crosssectional design, the direction of influence/impact could not be determined. Moreover, many studies concentrated on women and married employees, although it had been demonstrated that men and singles are also experiencing WFC (Grant-Vollent \& Donald, 2001). WFC studies in Malaysia are no exception (e.g. Ahmad, 1996; Noor, 1999, 2003). In these Malaysian studies, WFC was measured as unidirectional instead of bi-directional (i.e only examine the WFC direction and ignore the FWC direction) which did not capture the work-family conflict construct appropriately. Moreover these 
Malaysian studies concentrated on the outcomes of WFC (eg: job satisfaction, family satisfaction, happiness, well-being) and not the antecedents or determinants.

Therefore, this paper aims to examine the longitudinal relationship between WFC, FWC and their antecedents; i.e. demands and resources from job and family domains. As such the paper contributes to the work-family literature by investigating both directions of conflict on a heterogeneous sample using the longitudinal design in an Eastern cultural context. This study is based on the conceptual models developed by Frone, Russell and Cooper (1992), which emphasize the importance of distinguishing the direction of work-family conflict because the role-related antecedents of WFC may reside in the work domain, whereas the antecedents of FWC may reside in the family domain (Frone, 2003; Kinnunen \& Mauno, 2008). It is also important to identify the antecedents of conflict so that HR interventions can be designed and implemented to help employees in managing the conflict more effectively. Thus, the negative consequences of work-family and family-work conflicts on an individual employee, workplace and family can be minimized.

\section{Literature Review}

\section{Work-Family Conflict and its Antecedents}

WFC occurs when work-related responsibilities interfere with family activities. For instance, an employee may have to work long hours because of too much work and spend less time with the family; miss children sports day due to work and is too tired to help in the housework after work. This study is grounded on Frone's (2003) view that work and family are interrelated domains, that is, one domain will influence the other. Particularly, this study is based on the resource drain model which posits the negative relationship between work and family due to limited resources (time, energy, attention) in one domain (minimize the availability of the same resources to be utilized in another life domain) (Frone, 2003). The categorization of time, strain and behaviour-based WFC and FWC (eg. Carlson, Kacmar \& Williams 2000) is one example that supports the resource drain model. For instance, more hours spent at work will make it more difficult for an employee to fulfil his / her responsibilities at home. A lot of research shows, with the increase in working hours, employees experience higher work demands (Zhang \& Liu, 2011) which in the end contribute to WFC. 
Antecedents of WFC can be divided into three categories: (a) work domain variables; (b) non-work domain variables and (c) individual and demographic variables (Byron, 2005). This study only concentrates on the first two categories as these factors are easier to change than permanent personal factors (Kinnunen \& Mauno, 2008; Zhang \& Lui, 2011).

With regard to work domain variables, theories and research findings from Western countries have consistently demonstrated the link between job demands and WFC (Bruck, Allen \& Spector, 2002; Byron, 2005; Frone, Yardley \& Markel, 1997). Antecedents of WFC reside in the work domain, whereas FWC in the family domain (Byron, 2005; Frone, 2003; Kinnunen \& Mauno, 2008). Job demands found to be predictors of WFC are work pressure (Grzywacz \& Marks, 2000) and long hours (Spector et al., 2007). For both the Taiwanese and the British, work demands were positively related to WFC, whereas family demands were positively related to FWC (Luo, Robin, Shu-fang $\&$ Mao-Thing 2006). In a similar vein, longitudinal studies at one year apart among Dutch male employees demonstrated that psychological job demands, physical demands and emotional demands increased the risk for future WFC (Jansen, Kant, Kristensen \& Nijhuis 2003).

In addition, researchers have also studied the relationship of some work-related factors, such as work demand, work devotion, workdedication and WFC (Zhang \& Liu, 2011). Hall and Ritcher (1988) as cited in Zhang \& Liu (2011) stated that the more an individual devotes himself into the work role, the greater the possibility he may bring work problems back home, and the bigger the WFC. In other words, high devotion to work is unavoidable to cause individual sacrifice of family life and to result in WFC (Zhang \& Liu, 2011).

On the contrary, job resources (high levels of autonomy and respect, meaningful work) showed negative relationship to WFC (Voydanoff, 2004). Similarly a longitudinal study among Dutch employees revealed that supervisors' and co-workers' support had protective effect against future WFC (Jansen et al., 2003). Based on previous evidence (e.g. Bruck, Allen \& Spector, 2002; Byron, 2005; Jansen et. al., 2003; Voydanoff, 2004); we proposed:

H1: Job demands will be positively related to work-family conflict, whereas job resources will be negatively related to work-family conflict. 


\section{Family-Work Conflict and Its Antecedents}

FWC arise when family tasks and activities hinder work responsibilities. Examples of FWC include being absent from work to deal with family responsibilities, being occupied with family problems while at work and declining to travel because of child-caring activities.

Contrary to the theoritical expectation, Byron (2005) in her metaanalytic review of 60 studies found that the corelation between FWC and family domain were not more strongly related than their corelation with WFC. In other words, corelation between antecedents from the family domain and FWC have similar strength as the corelation between antecedents from the family domains and WFC. Only a few family-related antecedents i.e. hours of non-work activities, family stress, number of children and marital status are reported to relate more strongly to FWC than to WFC. For instance, levels of FWC are higher among those with children than those without children (Grzywacs \& Marks, 2000); employees with low social support and control in the family situation (Demerouti, Guerts \& Kompier, 2004). In addition, in their longitudinal study, Grandey and Cropanzano (1999) demonstrated that having children at home and greater family role stress are related to an increase in FWC. Guerts et al. (2005) found that relatively high levels of home demands and low levels of home support were associated with relatively high levels of negative FWC.

In contrast, Che Rose, Loo See, Uli and Idris (2006) in their study among 475 managers and executives in Selangor, Malaysia, reported that having harmonious successful home environments from spousal and family support is highly valued, which could lead to less FWC. The reason why family demand influences WFC is the variety of stresses produced as family demand is satisfied, such as role overload related to family role involvement, role conflict and role vagueness (Zhang \& Liu, 2011). This stress from family level reduces the resources that can be used in the work field. The individual worker, who spends a lot of time on the family and takes on more family roles, will feel lack of working time and energy. High-level family demands may require individuals to spend more time on family affairs, which cause the related stress to increase and spill over to the work role (Zhang \& Liu, 2011). Based on this evidence, we proposed:

H2: Family demands will be positively related to FWC, whereas family resources will be negatively to related FWC. 
The conceptual model of the study is illustrated in Figure 1.

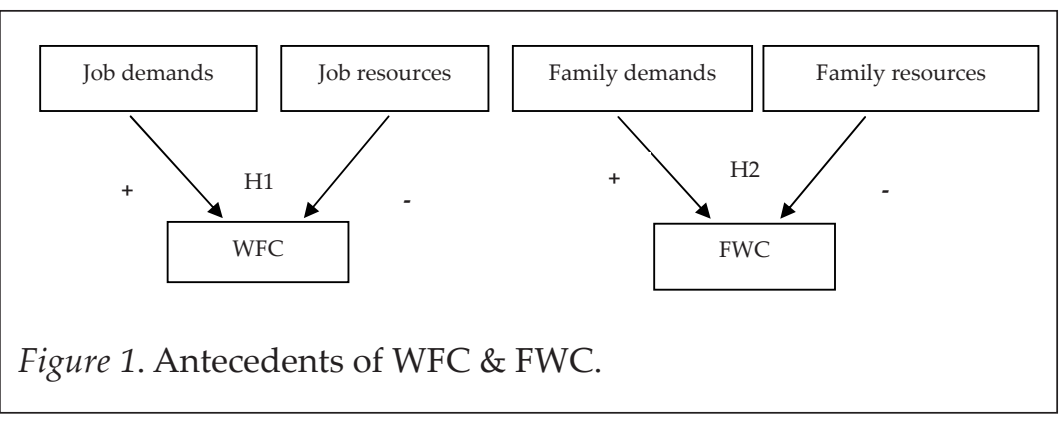

\section{Method}

\section{Participants and Procedure}

The population of this study is 1,000 employees from six public and private sectors from the forestry, manufacturing, telecommunication and service industries in Kuching, Sarawak, Malaysia. Simple random sampling was used to choose the respondents. The respondents were contacted through their human resource managers and were asked to complete a voluntary self-administered questionnaire each. Included with the questionnaire were an endorsement letter from the Sarawak State Planning Unit, a central body that governs all the organizations in the state, and an invitation to participate in the Time 2 study. The questionnaires were returned in sealed envelopes to the researcher through the human resource manager two weeks after the distribution. A total of 506 employees responded, representing a response rate of 50.6 per cent at Time 1 (started in August 2006) and 296 responded at Time 2 (started in November 2006) (response rate of 58.5 per cent -296/506). The final sample did not differ significantly in terms of demographic characteristics at Time 1 and Time 2.

The majority of the respondents were male (56 per cent), nonexecutives (77 per cent), had permanent posts (82 per cent), were in the age group of 35 to 45 (36 per cent), were married for an average of 15 years (53 per cent) with 1 to 9 children ( 80 per cent), and had a working spouse (50 per cent). 39 per cent had 11 years of education, with 15per cent having Bachelors degrees. The length of time working in the organizations ranged from 1 to 39 years, with a mean of 12.63 years. Nearly half (45 per cent) were Malays and 50 per cent were Muslims, which reflect the Malaysian national population composition. 


\section{Measures}

\section{Work-family Conflict (WFC)}

WFC is defined as the negative effect of work-related responsibilities to family activities, while family-work conflict is defined as the negative effect of family-related responsibilities to work activities. Both WFC and FWC were assessed using the 18 items-WFC scale (Carlson, Kacmar \& Williams, 2000). Some examples of the items are 'I have to miss work activities due to the amount of time I must spend on family responsibilities' and 'The behaviours that work for me at home do not seem to be effective at work'. The items are scored on a 5-point scale $(1=$ strongly disagree to $5=$ strongly agree $)$. The current study found acceptable internal reliability for WFC and FWC, .86 and .85 at Time 1 and .83 and .84 at Time 2 respectively.

\section{Job Demands}

Job demands are defined as challenges faced in order to complete the responsibilities at work which include work demands, work overload and work involvement. Job demand measures are work demands (5 items from Voydanoff, 2004), work overload (2 items from Foley, Hang Ye \& Lui, 2005) and work involvement (4 items from Carlson \& Perrewe, 1999 and Hyman, Scholarios \& Baldry, 2005) are scored on a- 6 point Likert scale $(1=$ strongly disagree to $6=$ strongly agree $)$. Sample items include 'My work load is too heavy', 'I never seem to have enough time to get everything done in my job' and 'I am very much involved in my job role'. All items are averaged and higher scores indicate higher demands $(\alpha=.93)$.

\section{Family Demands}

Family demands are defined as challenges faced in order to fulfil the family responsibilities. Family demands in this study consist of family time commitment and family overload (Peeters, Montgomery, Bakker \& Schaufeli, 2005). It was assessed on a-5-point scale ( $1=$ never to $5=$ always). Sample questions are 'I never seem to have enough time to get everything done at home' and 'I have to do many things in a hurry when I am at home' $(\alpha=.83)$.

\section{Job Resources}

Job resources are defined as support received at the workplace to assist with task completion. Job resources in this study measure support 
from supervisors (5 items - Voydanoff, 2005), co-workers, (4 items - Voydanoff, 2004), usefulness of WF policies (3 items - Lambert, 2000) and work autonomy (6 items - Voydanoff, 1988) using a 6-point scale $(1=$ strongly disagree to 6 = strongly agree $)$. Sample items include 'My supervisor accommodates me when I have family or personal business to take care of' and 'My organization work-life balance policies make it easier for me to balance my work and personal life'. All scores are summed and higher scores indicate higher support at work. $(\alpha=.84)$.

\section{Family Resources}

Family resources are defined as support received from family members in order to fulfil family- related obligations. Family support is measured via the Family Support Inventory for Workers (King, Mattimore, King \& Adams, 1995). The 16 items encompass both emotional and instrumental assistance and are scored on a 5-point scale $(1=$ strongly disagree to $5=$ strongly agree $)$. Item includes 'Members of my family are interested in my job' $(\alpha=.86)$.

\section{Analysis}

\section{Analytical Strategy}

First, we screen the data by deleting outliers (as suggested by Kline, 2005) by inspecting the frequency distribution of the $z$ scores. Data with $z$ scores outside -3 and +3 were deleted. Only 277 valid cases from 296 respondents (matched Time 1 and Time 2 respondents) (without outliers) were included in the final analysis.

Secondly, we conducted the confirmatory factor analysis (CFA), followed by correlation and hypotheses testing. CFA and hypotheses testing were examined by the structural equation modelling (SEM) using AMOS 7.0 through the Maximum Likelihood Estimation procedure.

Thirdly, we examined the measurement model for each latent measure. For demands, the two-factor model (demands from work and family) with correlations between factors was found to provide a reasonable fit to the data and better than a 1-factor model of demands $\left(\Delta \chi^{2}(6)=1167.62 p<.001\right)$. Factor loadings for demand items ranged from .51 to .91 and all were significant at .001 . 
For resources, the two-factor model (resources from work and family) with correlation between factors was found to provide a reasonable fit to the data and better than a 1 -factor model of resources $\left(\Delta \chi^{2}(1)=\right.$ $1035.34 p<.001)$. Factor loadings for resource items ranged from .40 to .80 and all were significant at .000 .

\section{Results}

Using the Pearson Produce Moment Corelation, we found that job demands had positive relationship with WFC $(\mathrm{r}=.20, p<.01)$ and FWC $(r=.12, p<.01)$ at Time 2 while job resources had negative relationship with WFC $(\mathrm{r}=-.19, p<.01)$ and FWC $(\mathrm{r}=-.12, p<.05)$ at Time 2. The result demonstrated the cross-domain effect of job demands and resources and FWC. Family demands and resources were not significantly related to WFC and FWC.

Hypothesis 1 proposed that job demands will be positively related to WFC and job resources will be negatively related to WFC. The model had a moderate good fit to the data $-\chi^{2}(14)=30.23, p<.000 ; \chi^{2} / \mathrm{df}=$ 2.15; $\mathrm{CFI}=0.97, \mathrm{TLI}=0.97, \mathrm{RMSEA}=0.06)$ (see Figure 2 ). As predicted, job demands are positively related to $\operatorname{WFC}(\beta=.18, p<.01)$ and job resources are negatively related to WFC $(\beta=-.16, p<.01)$. The result fully supported Hypothesis 1.

Consistent with the correlation result, Hypothesis 2 which predicted the positive relationship between family demands and FWC and the negative relationship between family resources and FWC were not supported.

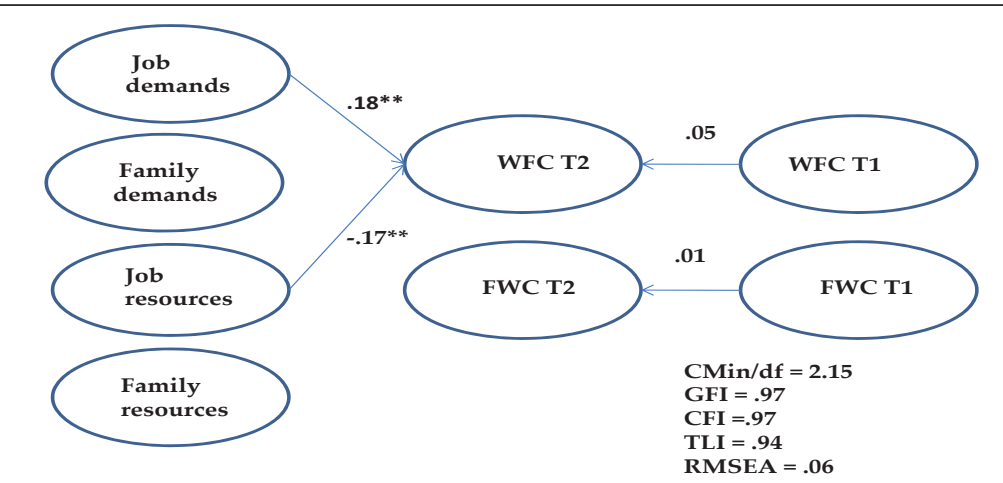

Figure 2. Structural model for demands and resources and conflict (longitudinal data).

Note. ${ }^{* *} \mathrm{p}<.01$; non-sig paths are not shown. 


\section{Discussion and Implications}

Although several Malaysian researchers have studied work-family conflict (e.g. Ahmad Zainal Abidin et al., 2010; Ahmad, 1996; Noor, 1999, 2006), the present study is one of the first to provide empirical evidence using longitudinal data (3 months apart) on a heteregenous sample. The goal of this study was to determine the causes of WFC and FWC from work and family demands and resources, and by the using longitudinal design, we were able to determine the direction of the relationship between the antecedents and WFC and FWC.

Consistent with the resource-drain perspective, we found that job demands were positively related to WFC over time, while job resources were negatively related to WFC over time.

Our finding provides support for the universality of relationship between job demands and WFC, as presented in previous researches. In this study we found that job demands (work demands, work overload and work involvement) cause more WFC. This is expected because high job demands require more time, energy and commitment at work, particularly for employees with high levels of work involvement. Thus high job demands contribute to time and strain-based WFC because it is difficult for an employee to prevent stress and pressure from the workplace into the family domain.

Job resources (support from supervisors, co-workers, family-friendly policies and job autonomy) were negatively related to WFC. In other words, job resources could act as buffers to work-family conflict; similar to previous findings (e.g: Dinger, Thatcher \& Stepina, 2010; Eng, Moore, Grunberg, Greenberg, \& Sikora, 2010). Having supportive supervisors and co-workers improve the employee's ability to respond effectively to multiple role demands and thereby decrease their perception of WFC. The finding emphasis the importance of organisation in creating a culture that is supportive to the family. By practicing family supportive culture in the organisation, support from supervisors and co-workers can be sought easily, which will lessen the experience of WFC.

In allocating work to employees, some autonomy should be granted as it will neutralize the high job demands and overload. By having some autonomy and flexibility such as how to carry out the job, who to work with and where to do the job, employees gain sense of control which increase their capacity to fulfil the demands, with minumum interuption to their family, thus lowering their perception of WFC. 
It is interesting to note that in this study, demands from the family domain did not predict FWC; contrasting other previous findings (eg: Demerouti et al., 2004; Guerts et al., 2005). One possible explanation is the Malaysian collectivist society; work and family domains are more integrated and permeable than the Western individualist society (refer Aycan, 2008; Hofstede, 1994). In individualist cultures people prefer to act as individuals, whereas in collectivist culture they act as members of an in-group (e.g. extended family). In individualist culture, the individual is expected to look after himself/herself, and relationships with parents or siblings may not last a lifetime. In contrast, in collectivist culture, the extended family forms a strong cohesive tie that protects the individual for a lifetime in exchange for loyalty and sharing of resources (e.g. income, house) (Hofstede \& Hofstede, 2005). Spending more time and energy in family activities is not perceived as a burden because the family is the most important in-group for the collectivist society (Hofstede \& Hofstede, 2005). Therefore, family demands were not perceived as pressure that would interfere with work responsibilities.

Family resources did not significantly predict FWC as reported in previous Eastern studies (eg: Aryee, Srinivas \& Tan, 2005). A possible explanation could be that although family support was available, it was not effective enough to combat FWC. This is because receiving support from the family comes at a cost; such as it can threaten an employee 's competence, become dependent on family members or become obliged to repay the support.

\section{Limitation and Future Research}

Although we utilized a longitudinal design, only work-family and family-work conflict variables are measured at both times. Future research could measure all variables (demands and resources as well conflict) at both times so that a stronger conclusion could be derived.

Future research could investigate the positive side of the work-family interaction -that is, work-family enrichment, facilitation, as recent studies demonstrated the benefits of the work-family interactions (eg. Voydanoff, 2004). This positive outcome of work and family interaction, is important to be highlighted so that organizations could create interventions to increase the positive sides of this work and family interface. Work-family enrichment is also in line with the positive psychology movement which is getting researchers' attention in this decade (Seligman \& Csikszentmihalyi, 2000). 
In addition, as the life domain encompasses other domains besides the family; future studies could examine the influence of other domains such as community, leisure and personal time in work-life interface; so a more holistic understanding of work and non-work could be obtained.

\section{Conclusion}

In conclusion, Malaysian employees in this study reported higher WFC than FWC. Job demands contribute to more WFC while job resources decrease WFC. The study however, did not find any significant predictors of FWC from the work and family demands and resources invesigated.

Therefore it is important for organisations to provide more job resources to employees in order to minimize the employees' experience of WFC. Job resources could be offered through familyfriendly policies and culture; supportive supervisors and co-workers as well as better job designs. Most importantly, the idea of having a balance between work and family should be promoted to all employees.

\section{Acknowledgment}

1. The paper was presented at the $5^{\text {th }}$ National Human Resource Conference, 8-10 June 2010, Kuala Terengganu, Malaysia, organised by UUM College of Business, Universiti Utara Malaysia.

\section{References}

Ahmad, A. (1996). Work-family conflict among married professional women in Malaysia. Journal of Social Psychology, 136, 663-665.

Ahmad Zainal Abidin, Abd Razak, Che Mohd Zulkifli, Che Omar \& Jamal Nordin, Yunus. (2010). Family issues and work-family conflict among medical officers in Malaysian public hospitals. International Journal of Business and Social Science, 1(1), 26-36.

Anonymous. (2010). Work-family conflict ignores middle class. Women in higher education, 19, 4-4.

Aryee, S., Fields, D., \& Luk, V. (1999). A cross-cultural test of a model of the work-family interface. Journal of Management, 25, 491-511.

Aryee, S., Srinivas, E. S., \& Tan, H. H. (2005). Rhythms of life: Antecedents and outcomes of work-family balance in employed parents. Journal of Applied Psychology, 90, 132-146. 
Aycan, Z. (2008). Cross-cultural approaches to work-family conflict. In K. Korabik, D. S. Lero, \& D. L. Whitehead (Eds.), Handbook of work-family integration: Research, theory and best practices (pp. 353-370). Boston: Academic Press, Elsevier.

Bruck, C. S., Allen, T. D., \& Spector, P. E. (2002). The relation between work-family conflict and job satisfaction: A finer-grained analysis. Journal of Vocational Behavior, 60, 336-353.

Byron, K. (2005). A meta-analytic review of work-family conflict and its antecedents. Journal of Vocational Behavior, 67, 169-198.

Carlson, D. S., Kacmar, K. M., \& Williams, L. J. (2000). Construction and initial validation of a multi- dimensional measure of workfamily conflict. Journal of Vocational Behavior, 56, 249-276.

Che Rose, R., Loo See, B., Uli, J., \& Idris, K. (2006). An analysis of quality of work life (QWL) and career-related variables. American Journal of Applied Sciences, 3, 2151-2159.

Demerouti, E., \& Geurts, S. A. E; Kompier, M.A.J., (2004). Positive and negative work-home interaction: Prevalence and correlates. Equal Opportunities International, 23, 6-35.

Dinger, M., Thatcher, J. B., \& Stepina, L. P. (2010). A study of workfamily conflict among IT professionals: Job characteristics, individual values, and management practices. Journal of Organizational Computing \& Electronic Commerce, 20(1), 91-121.

Eng, W., Moore, S., Grunberg, L., Greenberg, E., \& Sikora, P. (2010). What influences work-family conflict? The function of work support and working from home. Current Psychology, 29(2), 104-120.

Foley, S., Hang-Yue, N., \& Lui, S. (2005). The effects of work stressors, perceived organizational support, and gender on work-family conflict in Hong Kong. Asia Pacific Journal of Management, 22, 237-256.

Friedman, S. D., \& Greenhaus, J. H. (2000). Work and family - Allies or enemies? What happens when business professionals confront life choices? New York: Oxford.

Frone, M. R., Russell, M., \& Cooper, L. M. (1992). Antecedents and outcome of work-family conflict: Testing the model of the work-family interface. Journal of Applied Psychology, 77, 65-75.

Frone, M. R., Yardley, J. K., \& Markel, K. S. (1997). Developing and testing an integrative model of the work-family interface. Journal of Vocational Behavior, 50, 145-167.

Frone, M. R., Russel, M., \& Cooper, M. L. (1997). Relation of work and family conflict to health outcomes: A four-year longitudinal study of employed parents. Journal of Occupational $\mathcal{E}$ Organizational Psychology, 70, 325-335. 
Frone, M. R. (2003). Work-family balance. In J. C. Quick \& L. E. Tetrick (Eds.), Handbook of occupational health psychology (pp. 143-162). Washington: American Psychological Association.

Grandey, A. A., \& Cropanzano, R. (1999). The conservation of resources model applied to work-family conflict and strain. Journal of Vocational Behavior, 54, 350-370.

Grant-Vallone, E. J., \& Donaldson, S. I. (2001). Consequences of workfamily conflict on employee well-being overtime. Work $\mathcal{E}$ Stress, $15,214-226$.

Grzywacz, J. G., \& Marks, N. F. (2000). Reconceptualizing the workfamily interface: An ecological perspective on the correlates of positive and negative spillover between work and family. Journal of Occupational Health Psychology, 5, 111-126.

Grzywacz, J. G., \& Carlson, D. S. (2007). Conceptualizing work-family balance: Implications for practice and research. Advances in Developing Human Resources, 9, 455-471.

Guerts, S. A. E., Taris, T. W., Kompier, M. A. J., Dikkers, J. S. E., Van Hooff, M. L. M., \& Kinnunen, U. M. (2005). Workhome interaction from a work psychological perspective: Development and validation of a new questionnaire, the SWING. Work and Stress, 19, 319-339.

Hacker, S. K., \& . Doolen, T. L., (2003). Strategies for living: Moving from the balance paradigm. Career Development International, 8, 283-290.

Hall, D. T., \& Richter, J. (1988). Balancing life and home life: What can organizations do to help? Academy of Management Executive, 11, 213-223.

Hassan, Z., Dollard, M. F., \& Winefield, A. H. (2010). Work-family conflict in east vs. western countries. Cross-cultural Management: An International Journal, 17 (1), 30-49.

Hofstede, G. (1984). The cultural relativity of the quality of life concept. The Academy of Management Review, 9, 389-398.

Hofstede, G. (1994). Cultures and organizations: Intercultural cooperation and its importance for survival. Software of the mind. London: Harper Collins.

Hofstede, G., \& Hofstede, G. J. (2005). Cultures and organizations: Software of the mind. New York: McGraw-Hill.

Huang, Y.-H., Hammer, L. B., Neal, M. B., \& Perrin, N. A. (2004). The relationships between work-to-family conflict and familyto-work conflict: A longitudinal study. Journal of Family and Economic Issues, 25, 79-100.

Hyman, J., Scholarios, D., \& Baldry, C. (2005). Daddy, I don't like these shifts you're working because I never see you': Coping strategies for home and work. In D. M. Houston (Ed.), Work-life balance in the 21st century (pp. 122-146). New York: Palgrave MacMillan. 
Jansen, N. W. H., Kant, I., Kristensen, T. S., \& Nijhuis, F. J. N. (2003). Antecedents and consequences of work-family conflict: A prospective cohort study. Journal of Occupational and Environmental Medicine, 45, 479-491.

King, L. A., Mattimore, L. K., King, D. W., \& Adams, G. A. (1995). Family support inventory for workers: A new measure of perceived social support from family members. Journal of Organizational Behavior, 16, 235-258.

Kinnunen, U., \& Mauno, S. (2008). Work-family conflict individuals' lives: Prevalence, antecedents and outcomes. In K. Naswall, J. Hellgren \& M. Sverke (Eds.), The individual in the changing working life (pp. 126-146). New York: Cambridge University Press.

Kline, B. R. (2005). Principles and practice of SEM (2nd ed.) New York: The Guilford Press.

Lambert, S. J. (2000). Added benefits: The link between work-life benefits and organizational citizenship behavior. Academy of Management Journal, 43, 801-815.

Luo, L., Robin, G., Shu-Fang, K., \& Mao-Ting, H. (2006). A crosscultural study of work/family demands, work/family conflict and well-being: The Taiwanese vs British. Career Development International, 11, 9-27.

Noor, N. M. (1999). Roles and women's well-being: Some preliminary findings from Malaysia. Sex Roles, 41(314), 123-145.

Noor, N. M. (2006). Malaysian women's state of well-being: Empirical validation of a conceptual model. Journal of Social Psychology, 146, 95-115.

Peeters, M. C. W., Montgomery, A. J., Bakker, A. B., \& Schaufeli, W. B. (2005). Balancing work and home: How job and home demands are related to burnout. International Journal of Stress Management, 12, 43-61.

Seligman, M. E., \& Csikszentmihalyi, M. (2000). Positive psychology. An introduction. The American Psychologist, 55(1), 5-14.

Spector, P. E., Allen, T. D., Poelmans, S. A. Y., Lapierre, L. M., Cooper, C. L., O'Driscoll, M., et al. (2007). Cross-national differences in relationships of work demands, job satisfaction, and turnover intentions with work-family conflict. Personnel Psychology, 60, 805-835.

Voydanoff, P. (1988). Work role characteristics, family structure demands, and work/family conflict. Journal of Marriage and Family, 50, 749-761.

Voydanoff, P. (2004). The effects of work demands and resources on work-to-family conflict and facilitation. Journal of Marriage $\mathcal{E}$ Family, 66, 398-412. 
IJMS 19 (1), 135-150 (2012)

Voydanoff, P. (2005). The differential salience of family and community demands and resources for family-to-work conflict and facilitation. Journal of Family and Economic Issues, 26, 395-417.

Wang, P., Lawler, J. J., Walumbwa, F. O., \& Shi, K. (2004). Work and family conflict and job withdrawal intentions: The moderating effect of cultural differences. International Journal of Stress Management, 11, 392-412.

Yang, N., Chen, C. C., Choi, J., \& Zou, Y. (2000). Sources of work-family conflict: A Sino-U.S. comparison of the effects of work and family demands. Academy of Management Journal, 43, 113-123.

Zhang, J., \& Liu, Y. (2011). Antecedents of work-family conflict: Review and prospect. International Journal of Business and Management, 6(1), 89-103. 